\title{
A CERCARIA OF THE GENUS HAPLOCLADUS FROM NUCULA NUCLEUS (L.)
}

\author{
By W. J. Rees, D.Sc.
}

(Text-figs. I-2)

The cercaria described here was found on 21 April 1936, in twelve out of sixteen specimens of Nucula nucleus (L.) from Cawsand Bay, Plymouth Sound. The parasite was found by Dr Marie V. Lebour, who kindly gave me the infested molluscs for examination. I have thought it advisable to publish these notes, incomplete as they are, as it may not be possible for me to obtain further specimens of infested Nucula for some time to come.

The trematode was found to parasitize the digestive gland and gonad. The cercariae develop in irregularly shaped parthenitae which each contain from two to ten larvae in various stages of development. The parthenitae measure $0.9-2.0 \mathrm{~mm}$. in length.

The cercaria is very large and has a long, forked tail (Fig. I). The measurements on the left of Table I were made with an ocular micrometer when the living cercariae were slightly flattened under the pressure of a cover-slip.

The body is elongate in outline, with a slight constriction just behind the oral sucker, and reaches its greatest diameter opposite the ventral sucker. The pre-acetabular region of the body is highly muscular and capable of much extension and contraction. Near the posterior border of the oral sucker there are two blunt processes, ventro-lateral in position. In section, the body is somewhat cylindrical, and consequently it is almost impossible to obtain true measurements from living cercariae because different individuals could not be subjected to the same pressure under a cover-glass. The measurements given on the right of Table I are of mature cercariae fixed in Bouin's fluid without pressure, and supplement those of living cercariae.

The tail is longer than the body and consists of a proximal, muscular portion which divides distally to form two contractile caudal furcae (Fig. I). The oral sucker is well developed and has a slit-like mouth situated ventrally. It opens into the buccal cavity of the powerful oral sucker connecting with the pharynx. The oesophagus leads back in the median line and passes imperceptibly into the unbranched intestine. This passes to the right of the acetabulum and returns to the median line at the posterior end of the body, where it terminates. No anal pore opening into the excretory bladder was observed. The unbranched intestine is characteristic of trematodes of the genus Haplocladus Odhner, I9II.

The excretory bladder is $\mathrm{Y}$-shaped, thin-walled and filled with excretory granules of irregular shape. The horns of the bladder reach as far forward as the 
Table I. Measurements (in mm.) of the Cercaria of Haplocladus SP.

$\begin{array}{cc}\begin{array}{c}\text { Living } \\ \text { (under pressure } \\ \text { of cover-slip) }\end{array} & \begin{array}{c}\text { Fixed } \\ \text { (without pressure) }\end{array} \\ 0.25 & \mathrm{I} \cdot 10 \\ 0.55-70 & 0.75 \\ 0.50 & - \\ 0.20-0.30 & 0.20 \\ \mathrm{I} \cdot 10-1.70 & \mathrm{I} \cdot 00 \\ 0.15-0.17 & - \\ 0.60-0.75 & 0.15-0.40 \\ 0.12-0.15 & 0.08-0.09 \\ 0.08-0.10 & 0.07-0.075 \\ 0.07-0.10 & 0.08-0.09 \\ 0.05-0.09 & 0.05-0.055\end{array}$
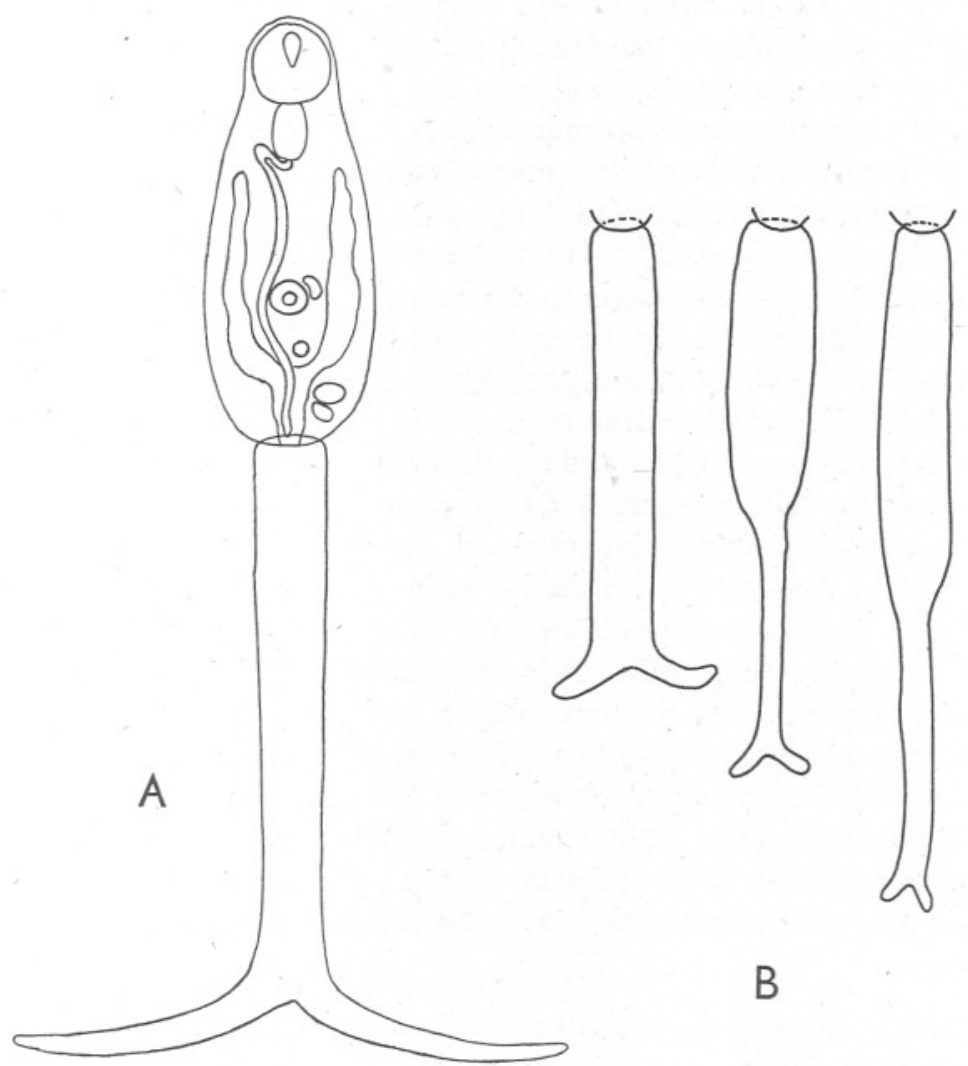

B

Fig. I. Cercaria of Haplocladus. A, ventral view under slight pressure of cover-slip; Plymouth, 2I April I936. B, different shapes assumed by the tail during $10 \mathrm{~min}$. 
posterior end of the pharynx (Fig. 2). Each main excretory duct opens into the horns of the bladder near their anterior end. The main excretory tubule, which is flagellated, passes postero-laterally for a short distance and then divides to form anterior and posterior collecting tubules. The position of a number (but not all) of the flame-cells was determined; these are indicated in Fig. 2, those of one side only being shown.

The ovary appears as a small, round body midway between the acetabulum and the posterior end of the body. The two testes are situated one in front of the other, lateral to the excretory bladder and near the posterior end of the body. There is a well-developed cirrus-pouch situated close to and anterolateral to the acetabulum. Penetration glands and cystogenous gland cells are absent, indicating that the metacercaria stage is probably very brief and that no encystment takes place.

The unbranched intestine and the position of the rudiments of the ovary and testes clearly indicate that the species belongs to the genus Haplocladus Odhner, I9II. The earliest and only record of a cercaria of this genus is that of Odhner (I9II), who found it in an aquarium with Nucula nucleus and Syndosmya at Kristineberg. His account of the larva is insufficient to allow a comparison to be made with the present specimens. He refers his cercaria to Haplocladus minor, but did not prove this experimentally. It is possible that the Plymouth cercaria may belong to

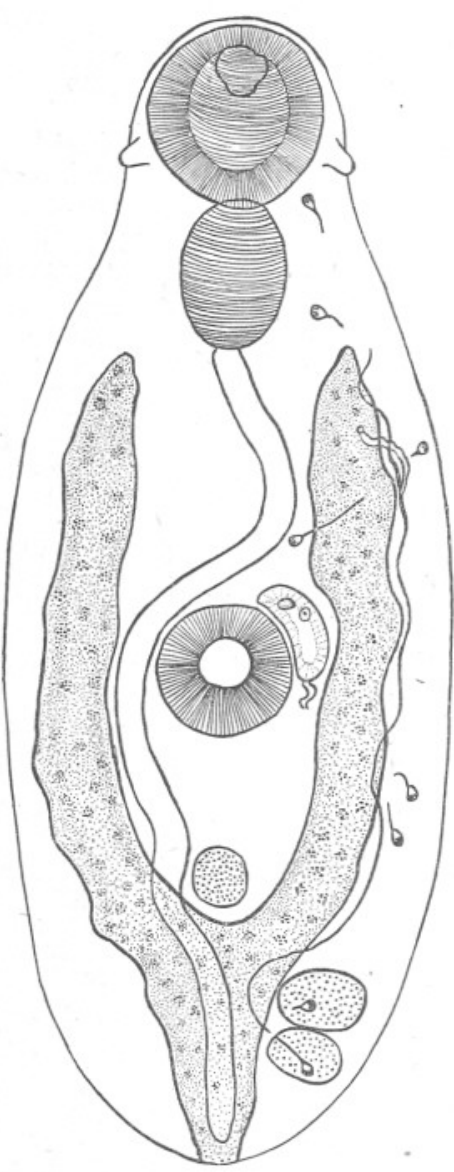

Fig. 2. Cercaria of Haplocladus species: detail of body, tail omitted. the common species of Haplocladus, H. typicus Odhner, which I have found in the intestine of Caranx trachurus from the same locality.

La Valette St George (1855) figures a Cercaria dichotoma which shows a remarkable similarity to the present species. Odhner is probably correct in regarding it as the larva of Tergestia laticollis (Rud.), which is closely related to Haplocladus.

\section{REFERENCES}

La Valette St George, A., I855. Symbolae ad trematodum evolutionis historiam. Inaug. Diss., Berlin.

OdHNER, T., I9II. Zum natürlichen System der digenen Trematoden. III. Zool. Anz., Bd. xxxviII, pp. 99-II7. 